\title{
Activation of TRPV1 channel by dietary capsaicin improves visceral fat remodeling through connexin43-mediated $\mathrm{Ca}^{2+}$ Influx
}

Jian Chen ${ }^{\dagger}$, Li Li ${ }^{\dagger}$, Yingsha Li, Xia Liang, Qianqian Sun, Hao Yu, Jian Zhong, Yinxing Ni, Jing Chen, Zhigang Zhao, Peng Gao, Bin Wang, Daoyan Liu, Zhiming Zhu* and Zhencheng Yan ${ }^{*}$

\begin{abstract}
Background: The prevalence of obesity has dramatically increased worldwide and has attracted rising attention, but the mechanism is still unclear. Previous studies revealed that transient receptor potential vanilloid 1 (TRPV1) channels take part in weight loss by enhancing intracellular $\mathrm{Ca}^{2+}$ levels. However, the potential mechanism of the effect of dietary capsaicin on obesity is not completely understood. $\mathrm{Ca}^{2+}$ transfer induced by connexin43 (CX43) molecules between coupled cells takes part in adipocyte differentiation. Whether TRPV1-evoked alterations in Cx43-mediated adipocyte-to-adipocyte communication play a role in obesity is unknown.
\end{abstract}

Materials and methods: We investigated whether Cx43 participated in TRPV1-mediated adipocyte lipolysis in cultured 3T3-L1 preadipocytes and visceral adipose tissues from humans and wild-type (WT) and TRPV1-deficient $\left(\mathrm{TRPV}^{-1-}\right.$ ) mice.

Results: TRPV1 and CX43 co-expressed in mesenteric adipose tissue. TRPV1 activation by capsaicin increased the influx of $\mathrm{Ca}^{2+}$ in 3T3-L1 preadipocytes and promoted cell lipolysis, as shown by Oil-red O staining. These effects were deficient when capsazepine, a TRPV1 antagonist, and 18 alpha-glycyrrhetinic acid (18a-GA), a gap-junction inhibitor, were administered. Long-term chronic dietary capsaicin reduced the weights of perirenal, mesenteric and testicular adipose tissues in WT mice fed a high-fat diet. Capsaicin increased the expression levels of p-CaM, Cx43, CaMKII, PPARS and HSL in mesenteric adipose tissues from WT mice fed a high-fat diet, db/db mice, as well as obese humans, but these effects of capsaicin were absent in TRPV $1^{-1-}$ mice. Long-term chronic dietary capsaicin decreased the body weights and serum lipids of WT mice, but not TRPV1 $1^{-1-}$ mice, fed a high-fat diet.

Conclusion: This study demonstrated that capsaicin activation of TRPV1-evoked increased $\mathrm{Ca}^{2+}$ influx in Cx43-mediated adipocyte-to-adipocyte communication promotes lipolysis in both vitro and vivo. TRPV1 activation by dietary capsaicin improves visceral fat remodeling through the up-regulation of $\mathrm{C} \times 43$.

Keywords: TRPV1, Cx43, Obesity, Ca ${ }^{2+}$, Visceral fat remodeling

\section{Background}

Obesity is the result of sustained mismatches that favor caloric intake over caloric expenditure. The prevalence of obesity during the last few years has dramatically increased worldwide [1]. In addition to many other disorders, obesity greatly increases the risk of developing a metabolic

\footnotetext{
* Correspondence: zhuzm@yahoo.com; zhenchengyan@sina.com

${ }^{\dagger}$ Equal contributors

Center for Hypertension and Metabolic Diseases, Department of Hypertension and Endocrinology, Daping Hospital, Third Military Medical University, Chongqing Institute of Hypertension, Chongqing 400042, China
}

syndrome and is associated with decreased life expectancy and increased health costs [2]. For these reasons, obesity has attracted increasing attention across multiple scientific disciplines. Although the adipose tissue of obese animals and humans is increased at both subcutaneous and visceral sites, visceral fat is responsible for the metabolic consequences of obesity [3]. The reasons for this effect are unclear. Visceral fat mass is closely related to the metabolic consequences of obesity; visceral adipose tissue depots are key correlates of the metabolic abnormalities associated with being overweight/obese, including inflammation. The 
release of cytokines, particularly IL-6, from fat cells may stimulate the proinflammatory state that characterizes obesity. The increased secretion of prothrombin activator inhibitor- 1 from fat cells may play a role in the procoagulant state of obesity and, along with changes in endothelial function, may be responsible for the increased risk of cardiovascular disease and hypertension [4-6].

Capsaicin, the major pungent ingredient in hot peppers, is a potent agonist for the transient receptor potential vanilloid 1 (TRPV1) channel, also called the capsaicin receptor. TRPV1 is a non-selective cation channel with a preference for cations; it transduces signals for the sensations of noxious heat and pain [7]. TRPV1 is highly expressed in sensory neurons and in vasculature, adipose, and liver tissues [8-10]. The earlier studies from human showed an increase in diet-induced-thermogenesis and lipid oxidation when high fat diet with capsaicin [11,12]. But studies of TRPV1 in weight loss present mixed results and the controversies. Marshall N J, et al, their results do not support the concept that TRPV1 plays a major role in influencing weight gain [13]. Gram DX, et al found that capsaicin had no effect on Zucker diabetic fatty (ZDF) animals weight loss, and the terminal body weight of the capsaicin-treated rats was significantly higher than that of the vehicle-treated ones [14]. An increase in energy expenditure after capsaicin in take was supported by studies by various investigators [15-17]. Some studies revealed a role for TRPV1 in promoting fat accumulation and weight gain because long-term TRPV1 antagonists or agonists administration can promote TRPV1 desensitization $[18,19]$. Our previous studies detected TRPV1 channels in 3T3-L1-preadipocytes and visceral adipose tissue from mice and humans. Activation of TRPV1 channels by capsaicin prevented adipogenesis and obesity [20] and nonalcoholic fatty liver disease [21]. However, the potential mechanism of the effect of dietary capsaicin on visceral fat accumulation and remodeling is not completely understood.

Gap-junctional communication (GJC) plays critical roles in cell growth and differentiation. Gap junctions allow the transfer of ions and small molecules between coupled cells and enable individual cells to communicate with their neighbors and match the immediate needs of coupled cells within a cluster [22]. The major component of gap junctions is connexin43 (Cx43), which exists in almost all tissues and in 3T3-L1 cells; this molecule allows for cellto-cell communication. Intracellular $\mathrm{Ca}^{2+}$ is one of the important signals in adipogenesis and regulates $\mathrm{Cx} 43$ function in adipocytes. The expression of Cx43 is downregulated at the transcriptional level during adipogenesis in the H-1/A cell line, a marrow stromal cell line that differentiates into adipocytes [23]. More recently, Yanagiya et al. reported that functional gap junctions are required for progression through a specific early stage of the 3T3-
L1 preadipocyte differentiation program. However, the role of Cx43 is different during the later stages of adipogenesis, particularly during adipocyte maturation. Inhibiting Cx43 degradation or constitutively over-expressing Cx43 blocks adipocyte differentiation via increases in intracellular ATP and $\left[\mathrm{Ca}^{2+}\right][24,25]$. Therefore, GJC plays some important roles in adipocyte differentiation and lipid metabolism. TRPV1-evoked alterations in Cx43-mediated adipocyte-to-adipocyte communication play an important role in obesity. Here, we show that the activation of TRPV1 by dietary capsaicin affects visceral fat accumulation and remodeling through a Cx43-mediated cell-to-cell intracellular $\left[\mathrm{Ca}^{2+}\right]$ increase.

\section{Materials and methods}

\section{Animal treatment and experimental procedures}

All mice (C57BL/6 WT mice, TRPV1 ${ }^{-1-}$ mice and $\mathrm{db} / \mathrm{db}$ mice) were purchased from Jackson Laboratory (Bar Harbor, Maine, USA). TRPV1 $1^{-/-}$mice which TRPV1 gene was knocked out in the whole body, not conditioned knockout we used in the experiments. WT and TRPV1 $1^{-1-}$ male mice were randomized into three groups respectively $(\mathrm{n}=15,5$ mice/cage) at 4-6 weeks of age, one group received standard laboratory chow, one group received high-fat diet, one group received high-fat diet plus $0.01 \%$ capsaicin. The high-fat diet supplied $49 \%$ of the calories as fat and $30 \%$ of the calories as carbohydrate. $\mathrm{Db} / \mathrm{db}$ male mice were randomized into two groups respectively $(n=6$, 6 mice/cage) at 4-6 weeks of age, one group received standard laboratory chow, the other group received standard laboratory chow plus $0.01 \%$ capsaicin. The standard laboratory chow diet provided $10 \%$ of the calories as fat and $68 \%$ as carbohydrate. All mice were housed in colony cages with a 12-hour light/12-hour dark cycle with free access to food and water for 5 months, body weight was measured every two weeks. At the end of 5 months, blood glucose was measured. Visceral fat was removed and weighted. Serum lipids were analyzed using routine techniques. All of the experiment procedures were performed in accordance with protocols approved by the Institutional Animal Care and Research Advisory Committee.

\section{Subjects Characteristics}

We recruited the obese male subjects and those were classified if waist circumference was more than $90 \mathrm{~cm}$ according to the Asian criteria of WHO Regional Office for the Western Pacific/International Association for the Study of Obesity/International Obesity Task Force. Age, body mass index, waist circumference were obtained. Visceral fat tissues were obtained from patients during regular scheduled cholecystectomy. Cholecystectomy had to be performed because of symptomatic gallstones. The protocol was approved by the local Ethics Committee. All subjects gave written informed consent. 


\section{Histopathologic examination}

The adipose tissue was cleaned with saline and weighted. Visceral fats from WT mice and human were observed with frost slice techniques and stained with anti-TRPV1 or Cx43 antibodies [20]. The TRPV1 and Cx43 in isolated 3T3-L1 preadipocytes or adipocytes primary cultured from visceral adipose tissue were identified by immunofluorescence stain. 3T3-L1 preadipocytes were cultured, fixed, and stained with the lipophilic dye oil-red O (Sigma-Aldrich). Red staining showed lipid droplets in the cytoplasm, indicating the number of lipid droplets in 3T3-L1 preadipocytes according to established techniques [26].

\section{Cell culture and adipocyte differentiation assay}

Murine 3T3-L1 preadipocytes were cultured and maintained in Dulbecco's modified Eagle's medium supplemented with $10 \%$ fetal calf serum (Hyclone) containing $100 \mu \mathrm{g} / \mathrm{ml}$ penicillin and $100 \mu \mathrm{g} / \mathrm{ml}$ streptomycin (GIBCO). Cells were plated and grown until 2 days post-confluence. Differentiation was then induced (day 0 ) by changing the medium to Dulbecco's modified Eagle's medium supplemented with $10 \%$ fetal calf serum, $0.5 \mathrm{mmol} / \mathrm{L}$ 3-isobutyl1-methylxanthine, $1 \mu \mathrm{mol} / \mathrm{L}$ dexarmethasone, and $10 \mu \mathrm{g} /$ $\mathrm{ml}$ insulin (Sigma-Aldrich). After 2 days the medium was replaced with the medium containing only $10 \mu \mathrm{g} / \mathrm{ml}$ insulin [27]. To confirm the functional properties of TRPV1 channels and Cx43 gap-junction on adipogenesis of 3T3-L1 preadipocytes, on the $8^{\text {th }}$ day after differentiation, the TRPV1 agonist capsaicin $(1 \mu \mathrm{mol} / \mathrm{L})$, or TRPV1 antagonist capsazepine $(1 \mu \mathrm{mol} / \mathrm{L})$, or inhibitor of $\mathrm{Cx} 43$ gap-junction 18 alpha-glycyrrhetinic acid $(18 \alpha-G A, 150 \mu \mathrm{mol} / \mathrm{L})$, (SigmaAldrich) were added to the medium for 24 hours as indicated [28]. Free fatty acids (FFA) (oleate/palmitate [PA], 2:1; Kelong Chemical Reagent Factory, Chengdu, China) were mixed with FFA-free bovine serum albumin, and the mixture was added to the medium to a final concentration of $1 \mathrm{mmol} / \mathrm{L}$ [21]. Intracellular accumulation of lipid droplets in 3T3-L1 preadipocytes were stained with Oil Red O $(0.5 \mathrm{~g}$ in $100 \mathrm{ml}$ isopropanol) at the day 3,5 , and 8 with or without differentiation.

\section{Intracellular free calcium measurement}

3T3-L1 cells grown on glass cover slips were loaded with $\mathrm{Ca}^{2+}$ indicator Fura-2 $(2 \mu \mathrm{mol} / \mathrm{L}$, Invitrogen, Paisley, UK) and $0.025 \%$ Pluronic F-127 in a physiological saline solution for $40 \mathrm{~min}$ at room temperature in the dark. $\left[\mathrm{Ca}^{2+}\right]_{i}$ was measured using a fluorescent plate reader (Varioskan Flash, Thermo) at $510 \mathrm{~nm}$ emission, with excitation wavelengths of $340 \mathrm{~nm}$ and $380 \mathrm{~nm}$. The changes in $\left[\mathrm{Ca}^{2+}\right]_{i}$ were calculated from the ratios of transient increases in fluorescence intensity at $340 \mathrm{~nm}$ and $380 \mathrm{~nm}[8]$.

\section{Fluorescence Recovery after Photo bleaching (FRAP)}

All fluorescent dyes emit light of one wave length (e.g. green) after they have absorbed light of another wave length (e.g. blue). However, if a very high intensity blue light is delivered to the dye, the dye will "photobleach" meaning that the high intensity light has rendered the dye unable to fluoresce. This phenomenon has lead to an interesting method called Fluorescence Recovery After Photobleaching (FRAP). The idea behind this method is to use FRAP to measure the ability of a molecule to move around over time. The percent recovery uses the formula: $(\mathrm{Y} / \mathrm{X}) \times 100=\%$ recovery. In the diagram, the percentage of fluorescence lost due to photo bleaching is $\mathrm{X}$ and the amount of fluorescence that returned to the bleached area is Y. FRAP evaluates the functional effect of gap junctions for intercellular communication between adjacent cells by dye coupling studies, in which photobleaching of cells loaded with a membrane-permeable fluorescence dye, 5, 6-carboxyfluorescein diacetate (5, 6-CFDA, Invitrogen Corp, Carlsbad, CA, USA), resulted in rapid recovery of fluorescence into the photobleached cell, within $10 \mathrm{~min}$ postbleaching $[29,30]$. After treatment, cells were rinsed twice with $1 \mathrm{ml}$ of Hank buffer and incubated with 5, 6CFDA ( $8 \mu \mathrm{g} / \mathrm{mL}$ in DMEM) at $37^{\circ} \mathrm{C}$ for 15 minutes, and quantitative imaging was excited at $488 \mathrm{~nm}$ by an argon ion laser and captured through a gating at 530/30 nm. The analyzed fluorescence recovery index is expressed as: $\mathrm{R}=(\mathrm{IR}-\mathrm{I} 0) /(\mathrm{Ii}-\mathrm{I} 0) \times 100 \%$. Fluorescence recovery was normalized with unbleached control to compensate fluorescence lost during the experiment [31].

\section{Immunoblotting analysis}

Immunoblotting of TRPV1, Cx43, p-CaM, CaMKII, PPAR $\delta$, HSL, $\beta$-actin and GAPDH were performed using standard techniques for adipose tissue and mature adipose cells. Primary antibody for TRPV1 was purchased from Alomone, Israel and other primary antibodies were from Santa Cruz Biotechnology (Santa Cruz, CA, USA). After incubation with the secondary antibodies for $1 \mathrm{~h}$, the proteins were detected by enhanced chemiluminescence and quantified using a Gel Doc 2000 Imager (Bio-Rad).

\section{Measurement of triglyceride and free fatty acid in cells}

Total lipids were extracted from 3T3-L1 preadipocytes using a chloroform-methanol $(2: 1, \mathrm{vol} / \mathrm{vol})$ mixture. Triglyceride and free fatty acid levels were quantified using ELISA kit (Applygen Technologies Inc., China) according to the manufacturer's instructions. Cell extracts were collected and centrifuged at the speed of $10000 \mathrm{rpm}$ for $15 \mathrm{~min}$ to obtain the supernatant. Then $100 \mu \mathrm{l}$ supernatant and $50 \mu \mathrm{l}$ enzyme conjugate were added to the provided 96-well plate for $1 \mathrm{~h}$ in $37^{\circ} \mathrm{C}$ while standard curve was made in the same plate. Afterwards, each well was washed with the diluted washing solution for 5 


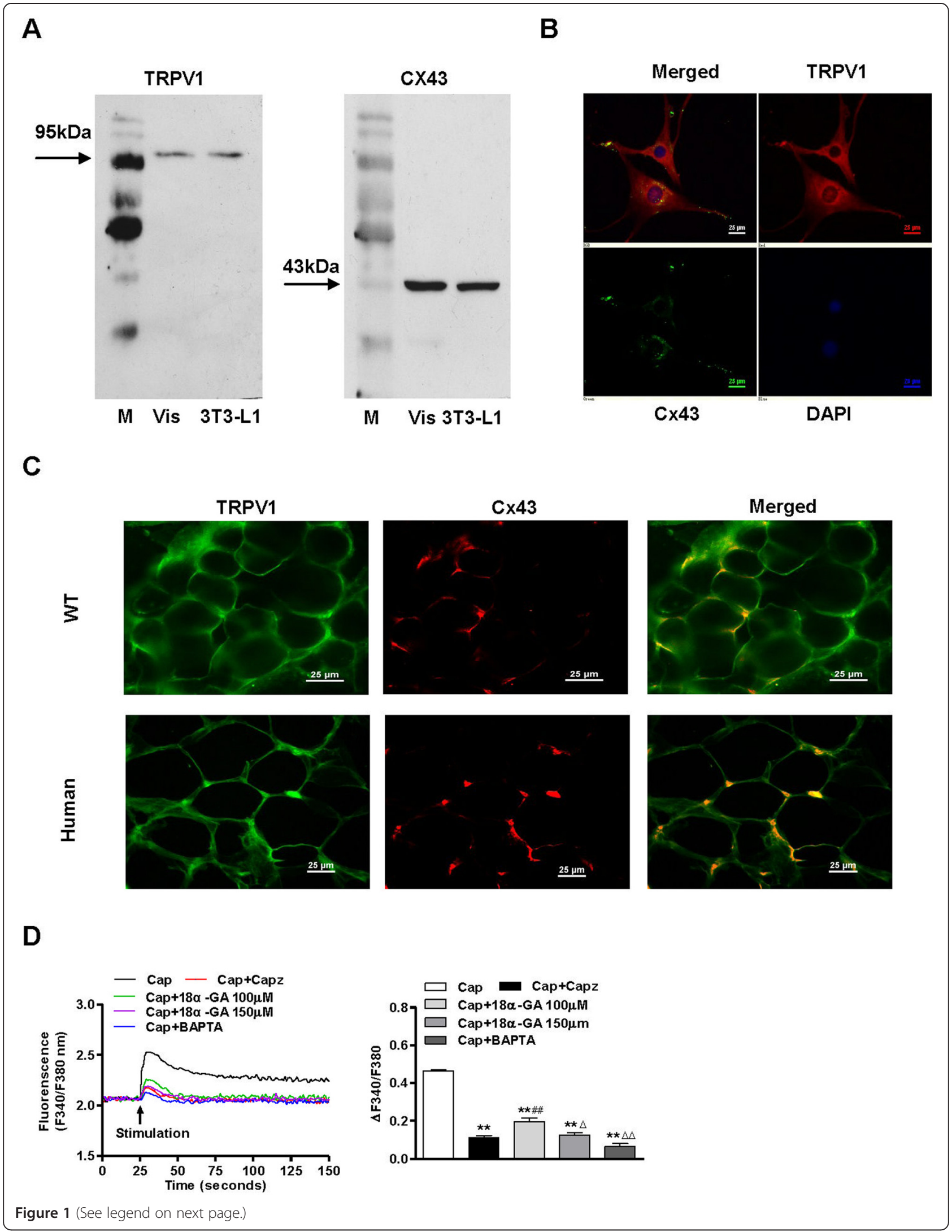


(See figure on previous page.)

Figure 1 Cx43 affects TRPV1-mediated $\mathrm{Ca}^{2+}$ influx in adipocytes. A. TRPV1 and Cx43 were detected in mesenteric adipose tissue (Vis) and 3T3-L1 preadipocytes (3T3-L1). M indicates the marker. B and C. Immunofluorescence demonstrated specific staining for co-expressed TRPV1 and Cx43 in the cell-cell connecting portions in primary cultured human visceral adipocytes $\mathbf{B}$ and visceral adipose tissues from both wild-type mice (WT) and humans $\mathbf{C}$. The green fluorescence indicates $\mathbf{C} \times 43$. The red fluorescence indicates TRPV1. Nuclei in all groups were stained in blue with DAPI. The images were collected using a Nikon TE2000-U inverted fluorescence microscope and are representative of 3 separate experiments. The scale bar indicates $25 \mu \mathrm{m}$. D. Representative curves (left panel) show $\left[\mathrm{Ca}^{2+}\right]_{i}$ changes in 3T3-L1 preadipocytes acutely stimulated with capsaicin (Cap, $\left.1 \mu \mathrm{mol} / \mathrm{L}\right)$, capsaicin with the TRPV1 antagonist capsazepine (Cap + Capz, $1 \mu \mathrm{mol} / \mathrm{L})$, the Cx43 inhibitor, 18a-glycyrrhetinic acid (Cap + 18a-GA, 100 or 150 $\mu \mathrm{mol} / \mathrm{L})$, or the intracellular $\mathrm{Ca}^{2+}$ chelator, BAPTA-AM $(10 \mu \mathrm{mol} / \mathrm{L})$. The summary data (right panel) show the maximal stimulated changes of $\left[\mathrm{Ca}^{2+}\right]_{i}(25-150 \mathrm{~s})$

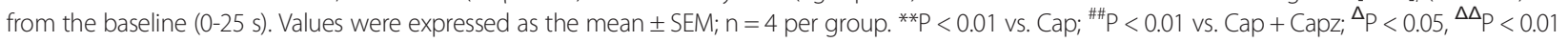
vs. Cap + 18a-GA $100 \mu \mathrm{M}$.

times, thoroughly pat dry with absorbent paper. Then $50 \mu \mathrm{l}$ substrate A and $50 \mu \mathrm{l}$ substrate B were successively added and the plate was incubated in $37^{\circ} \mathrm{C}$ for $15 \mathrm{~min}$. At last, stop solution $50 \mu \mathrm{l}$ was then added to each well and the OD450 values were measured with the Varioskan Flash, Thermo.

\section{Statistical analysis}

The data were expressed as the means \pm SEM from three to 3-15 independent experiments or mice. Comparisons between groups were analyzed using the Student's $t$ test or one-way ANOVA with Bonferroni's multiple comparison post hoc test (GraphPad Prism; La Jolla, CA, USA). Two-tailed $p$ values less than 0.05 were considered to indicate statistical significance.

\section{Results}

Functional TRPV1 co-expressed with Cx43 in mesenteric adipose tissues and 3T3-L1 preadipocytes

First, we detected TRPV1 and Cx43 in visceral adipose tissues from mice and 3T3-L1 preadipocytes by immunoblotting. The immunoblots confirmed the TRPV1 and Cx43 molecular weights at $95 \mathrm{kDa}$ and $43 \mathrm{kDa}$, respectively, and the antibodies identified TRPV1 and Cx43 in both mesenteric adipose tissues and 3T3-L1 preadipocytes (Figure 1A). Immunofluorescence demonstrated specific staining for co-expressed TRPV1 and Cx43 in the cell-cell connecting portions in primary cultured human visceral adipocytes and visceral adipose tissues from both wildtype mice (WT) and humans. The green fluorescence indicates $\mathrm{Cx} 43$. The red fluorescence indicates TRPV1. Nuclei in all groups were stained in blue with DAPI (Figure $1 \mathrm{~B}$ and $\mathrm{C}$ ). $\mathrm{C} \times 43$ is a gap junction protein, and $18 \alpha-$ GA is the gap-junction inhibitor widely used to inhibit gap junctional communication that is likely to enter cells and modify protein kinases that regulate Cx43 [32]. Capsazepine is a TRPV1 antagonist [33]. TRPV1 belongs to the family of nonselective cation channels that display high $\mathrm{Ca}^{2+}$ permeability. Acute exposure to capsaicin, a TRPV1-specific agonist, stimulated an increase in the cytosolic free calcium concentration $\left(\left[\mathrm{Ca}^{2+}\right]_{i}\right)$ in cultured 3T3-L1 preadipocytes. According to a previous study, calcium ions are most likely to travel through GJs, and the differential $\mathrm{Ca}^{2+}$ uptake into intracellular stores at high and low concentrations is influenced by slight time delays of $\mathrm{Ca}^{2+}$ traveling through the GJs. TRPV1-elicited Cx43 gap-junction assay showed that response of $\mathrm{Ca}^{2+}$ to capsaicin was completely inhibited by $150 \mu \mathrm{M} 18 \alpha-\mathrm{GA}$ in Cx43-expressing HeLa cells [34]. We found that the capsaicin-induced calcium increase could be inhibited by $18 \alpha-\mathrm{GA}$ at a concentration of $100 \mu \mathrm{mol} / \mathrm{L}$, whereas the maximum effect was obtained at $150 \mu \mathrm{mol} / \mathrm{L}$ in $3 \mathrm{~T} 3-\mathrm{L} 1$ preadipocytes. We also showed that $18 \alpha-\mathrm{GA}$ dosedependently inhibited calcium influx by capsaicin-induced activation of TRPV1, and that $18 \alpha-G A(150 \mu \mathrm{M})$ could completely block the increased calcium influx by capsaicin, as capsazepine effect in 3T3-L1 preadipocytes (Figure 1D). These results suggest that functional TRPV1 and Cx43 exist in adipose tissues and cells, both in humans and mice. Inhibition of TRPV1 and Cx43 reduces the increased free cytosolic calcium concentration $\left(\left[\mathrm{Ca}^{2+}\right]_{i}\right)$ in 3T3-L1 preadipocytes.

Inhibition of Cx43 reduces the cytosolic calcium increase induced by TRPV 1 activation and prevents adipolysis in 3 T3-L1 preadipocytes

Our previous study showes that the administration of capsaicin prevents obesity in male WT mice but not in $\mathrm{TRPV1}^{-/-}$mice fed a high-fat diet [20]. In the present study, we found that dietary capsaicin also reduced the weights of perirenal, mesenteric and testicular adipose tissues in WT mice but not TRPV1 ${ }^{-1-}$ mice fed a highfat diet (Figure 2A). Based on the previous findings by Zhang et al., TRPV1 activation by capsaicin increases intracellular calcium concentrations and prevents adipogenesis in 3T3-L1 preadipocytes. We evaluated the effects of $\mathrm{Cx} 43$ on lipid deposition which regulated by TRPV1 in 3T3-L1 preadipocytes. Adipogenesis was induced in 3T3-L1 preadipocytes, as described in our previous study [20]. Lipid droplets were visualized by Oil red O-staining in $3 \mathrm{~T} 3-\mathrm{L} 1$ preadipocytes on days 3, 5 , and 8 , with or without differentiation, in the absence (control condition) and presence of capsaicin (TRPV1 agonist), capsaicin plus 18 $\alpha$-GA (Cx43 gap-junction inhibitor), or capsazepine (TRPV1 antagonist) [24,25]. Maturation of the 3T3-L1 preadipocytes was induced by 
A

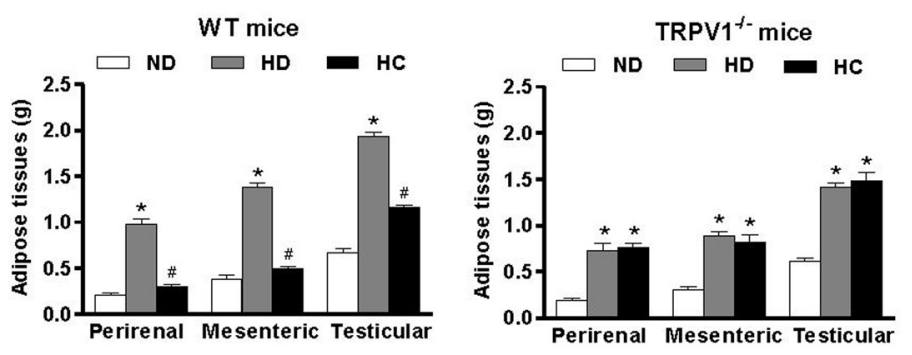

B

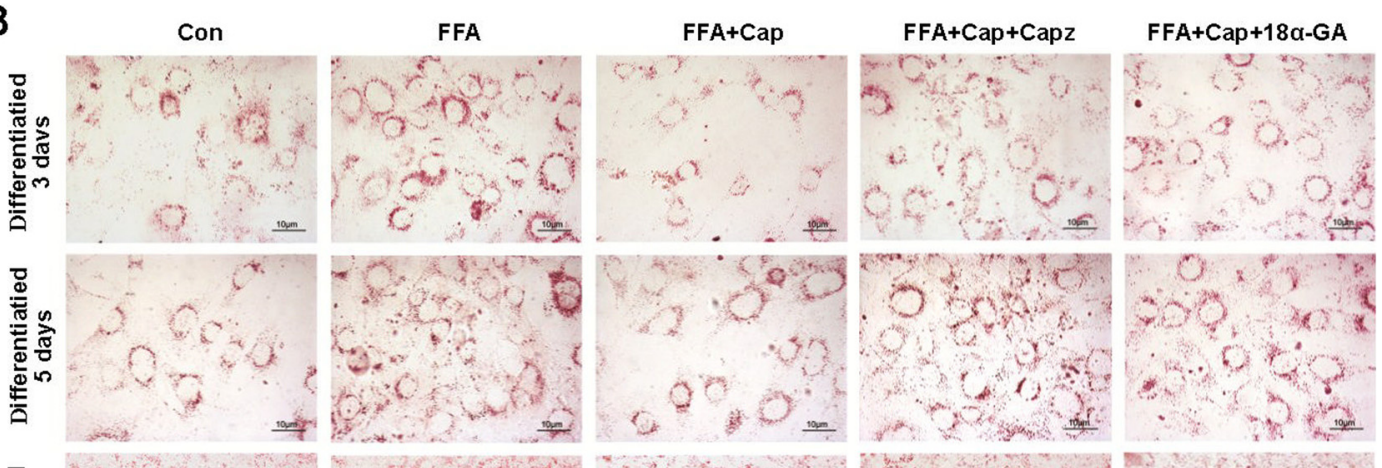

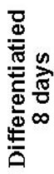
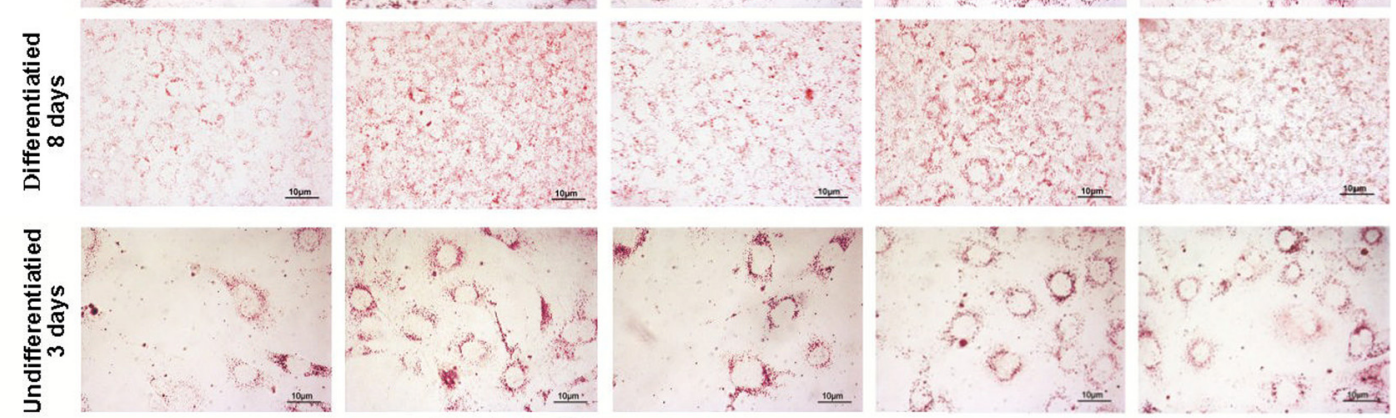

-
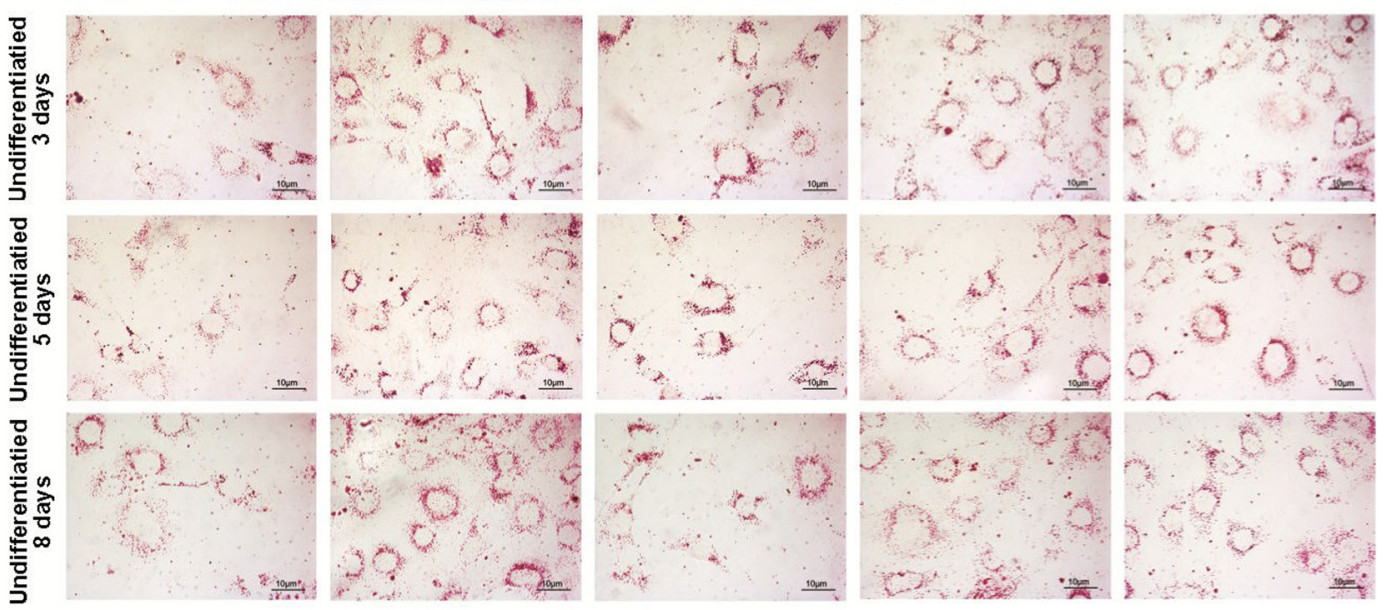

c

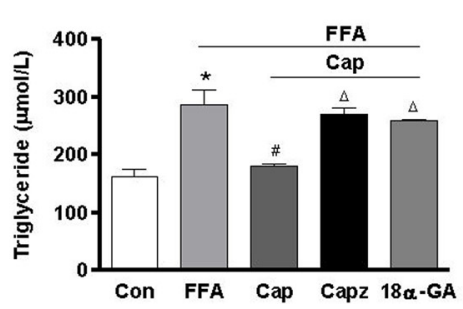

D

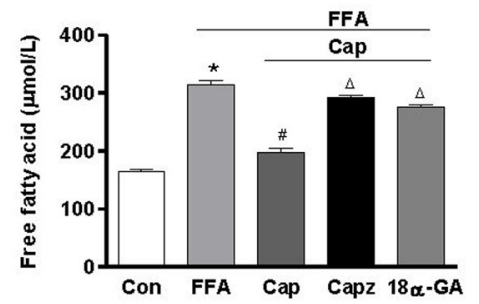

Figure 2 (See legend on next page.) 
(See figure on previous page.)

Figure 2 TRPV1 activation promotes lipolysis both in mesenteric adipose tissue and 3T3-L1 preadipocytes. A. The weights of mesenteric, perirenal and testicular adipose tissues from WT and TRPV $1^{-/-}$mice fed a normal diet (ND), a high-fat diet (HD), or a high-fat plus capsaicin diet (HC). ${ }^{*} P<0.05$ vs. ND, ${ }^{\#} P<0.05$ vs. HD. Values are expressed as the mean $\pm S E M, n=6$. B. Lipid droplets were visualized by Oil red $O$ staining of 3T3-L1 preadipocytes on days 3, 5, and 8, with or without differentiation. The cells were exposed to a mixture of 1 mmol/L long-chain free fatty acids (FFA) in the presence of $1 \mu \mathrm{mol} / \mathrm{L}$ capsaicin (FFA + Cap), capsaicin plus $1 \mu \mathrm{mol} / \mathrm{L}$ capsazepine (FFA + Cap + Capz) or 150 $\mu \mathrm{mol} / \mathrm{L}$ 18a-GA $(F F A+C a p+18 a-G A)$ for 24 h. Red spots indicate lipid droplets in the cells. Images are representative of 3 separate experiments. The scale bar indicates $10 \mu \mathrm{m}$. $\mathbf{C}$ and $\mathbf{D}$. Triglyceride and free fatty acid levels of 3T3-L1 preadipocytes after treatment with free fatty acids (FFA), FFA + capsaicin (Cap), FFA + capsaicin + capsazepine (Capz) or FFA + capsaicin + 18a-GA (18a-GA, $150 \mu \mathrm{mol} / \mathrm{L})$ for $24 \mathrm{~h} .{ }^{*} \mathrm{P}<0.05$ vs Con, ${ }^{\# P}<0.05$ vs FFA, ${ }^{\Delta} \mathrm{P}<0.05$ vs Cap. Values are expressed as the mean $\pm \mathrm{SEM} ; \mathrm{n}=3$ per group.

3-isobutyl-1-methylxanthine, dexamethasone, and insulin, as recommended. Free fatty acids (FFAs) increased the number of lipid droplets after maturation was induced. Capsaicin, the TRPV1 agonist (final concentration, $1 \mu \mathrm{mol} / \mathrm{L}$ ), reduced the amount of lipid droplets in 3T3-L1 preadipocytes. Furthermore, determination of cellular triglyceride levels confirmed that capsaicin prevented adipogenesis, whereas the administration of capsazepine or $18 \alpha-$ GA did not prevent adipogenesis in 3T3-L1 preadipocytes. The maximum effect of $18 \alpha-\mathrm{GA}$ was obtained at a concentration of $150 \mu \mathrm{mol} / \mathrm{L}$ in 3T3L1 preadipocytes (Figure 2B). We found that capsaicin induced an increase in the intracellular calcium levels and a decrease in triglyceride levels, which could be inhibited by capsazepine, a TRPV1 antagonist, at a concentration of $1 \mu \mathrm{mol} / \mathrm{L}$, or $18 \alpha-\mathrm{GA}$, a Cx43 gap-junction inhibitor, at a concentration of $100 \mu \mathrm{mol} / \mathrm{L}$; however, the maximum effect of $18 \alpha-\mathrm{GA}$ was obtained at $150 \mu \mathrm{mol} / \mathrm{L}$ in 3T3-L1 preadipocytes. The accumulations of triglyceride and free fatty acids did not significantly differ between FFA, FFA + Cap plus Capz and FFA + Cap plus 18 $\alpha-$ GA groups (Figure $2 \mathrm{C}$ and $\mathrm{D}$ ). Thus, we found that the administration of FFAs significantly increased the intracellular lipid droplets in 3T3-L1 preadipocytes, whereas capsaicin led to reduced intracellular lipid droplets. In contrast, the antagonism of TRPV1 or the inhibition of Cx43 abolished the effect of capsaicin on the adipolysis of preadipocytes. Based on these experiments, it was concluded that the capsaicin-induced cytosolic calcium increase through TRPV1 channels promoted adipolysis associated with Cx43-mediated $\mathrm{Ca}^{2+}$ influx.

TRPV1 promotes lipolysis of 3T3-L1 preadipocytes by regulating $\mathrm{Cx} 43$-mediated intracellular calcium levels Fluorescence Recovery After Photobleaching is used to measure the dynamics of Cx43 mobility. We used the gap-FRAP method to study the effect of TRPV1 on Cx43 in 3T3-L1 preadipocytes. The results showed that the inhibition of both TRPV1 and Cx43 induced few changes outside and little recovery of fluorescence inside the bleached regions in 3T3-L1 preadipocytes treated with both Capsazepine and 18 $\alpha$-GA, which damaged the dynamics of Cx43 mobility (Figure 3A and B). The 3T3L1 preadipocytes were treated with free fatty acids
(FFA), FFA + capsaicin (Cap), FFA + capsaicin plus TRPV1 antagonist capsazepine (Capz), FFA + capsaicin + ethyleneglycol-bis (beta-aminoethylether)-N, N'-tetraacetic acid (EGTA, calcium chelator), FFA + capsaicin + 18 $\alpha-$ GA $(18 \alpha-G A, 150 \mu \mathrm{mol} / \mathrm{L})$ or FFA + capsaicin plus PPAR $\delta$ inhibitor GSK0660 $(10 \mu \mathrm{mol} / \mathrm{L})$ for $24 \mathrm{~h}$. The drug intervention showed that TRPV1 activation by capsaicin led to the up-regulation of Cx43, CaMKII, PPAR $\delta$ and HSL. Inhibition of TRPV1 or Cx43 by capsazepine or 18 $\alpha$-GA and exposure to EGTA mediated the downregulation of Cx43, CaMKII, PPAR $\delta$ and HSL in 3T3L1 preadipocytes (Figure 3C). These results indicated that TRPV1 activation by capsaicin increased intracellular calcium associated with Cx43 function and promoted lipolysis in 3T3-L1 preadipocytes.

\section{TRPV1 activation by capsaicin increases $\mathrm{C} \times 43$ mediated} lipolysis of visceral adipose tissue in humans and mice We further studied the effects of chronic dietary capsaicin on $\mathrm{p}-\mathrm{CaM}, \mathrm{Cx} 43$, CaMKII, PPAR $\delta$ and HSL in visceral adipose tissue from WT mice or TRPV1 ${ }^{-1-}$ mice fed a high-fat diet and mesenteric adipose tissue from obese or lean human male subjects. The results showed that, compared with a normal diet, a long-term high-fat diet significantly reduced the protein expression levels of pCaM, Cx43, CaMKII, PPAR $\delta$ and HSL in mesenteric adipose tissues from WT mice, but that these effects were reversed by chronic dietary capsaicin. In contrast, the effects of dietary capsaicin on the up-regulation of p-CaM, Cx43, CaMKII, PPAR $\delta$ and HSL in visceral adipose tissue were absent in TRPV1 ${ }^{-/}$mice fed a high-fat diet plus capsaicin (Figure 4A). Furthermore, we also confirmed that the expression levels of TRPV1, p-CaM, Cx43, CaMKII, PPAR $\delta$ and HSL in mesenteric adipose tissue from obese human male subjects were significantly decreased compared with age-matched lean male subjects. The protein expression levels of TRPV1, p-CaM, Cx43, CaMKII, PPAR $\delta$ and HSL were significantly decreased in the mesenteric adipose tissue from obese male subjects, but were reversed after the adipose tissue was treated with capsaicin for $24 \mathrm{~h}$ (Figure 4B). The expression levels of TRPV1, p-CaM, Cx43, CaMKII, PPAR $\delta$ and HSL in mesenteric adipose tissue from $\mathrm{db} / \mathrm{db}$ mice were decreased compared with those from WT mice fed a normal diet 


\section{A}
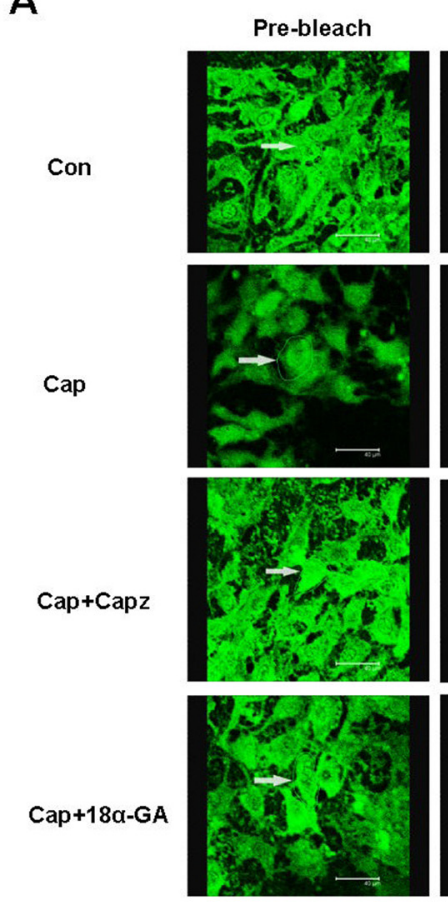

C
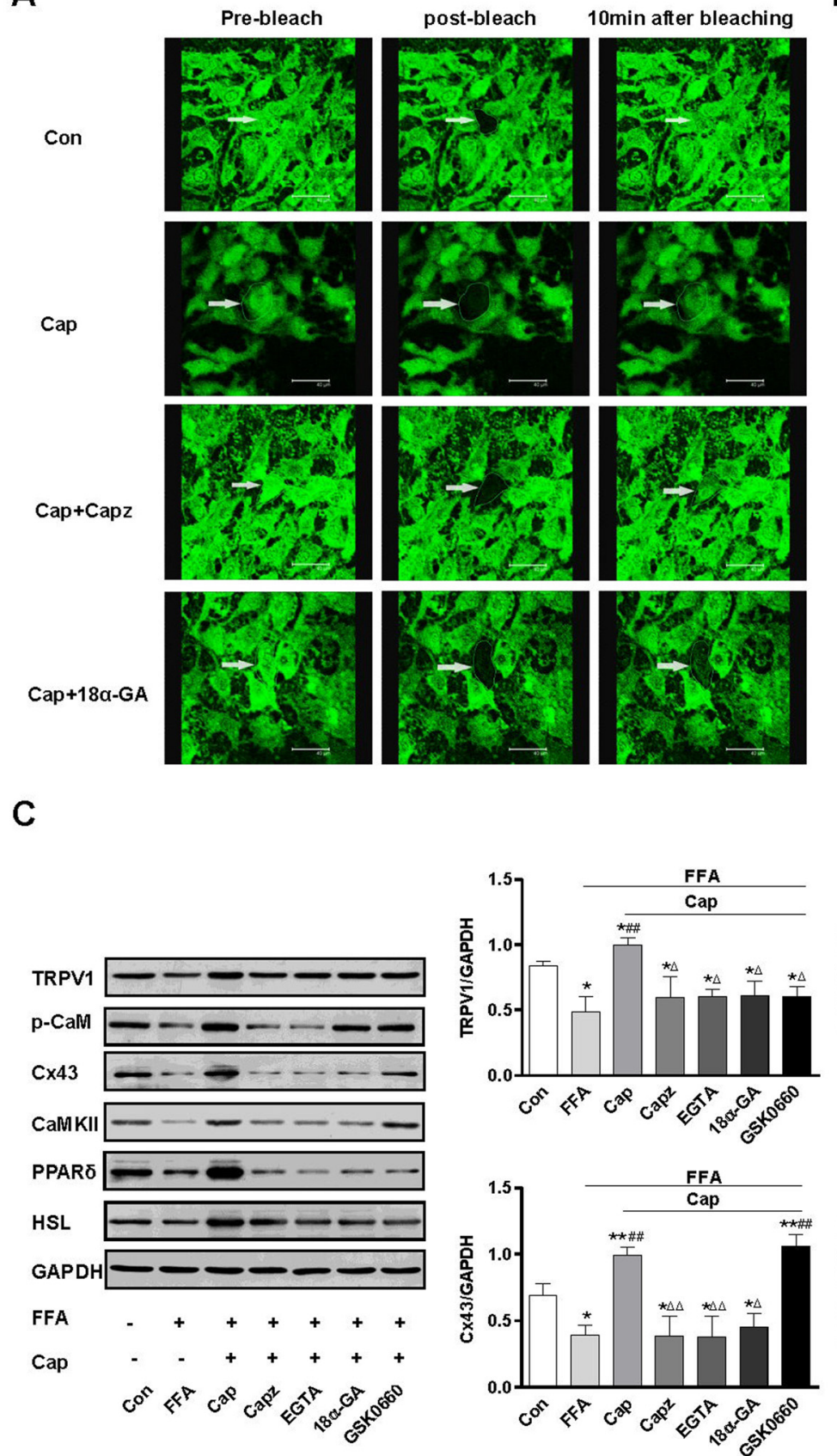

$10 \mathrm{~min}$ after bleaching
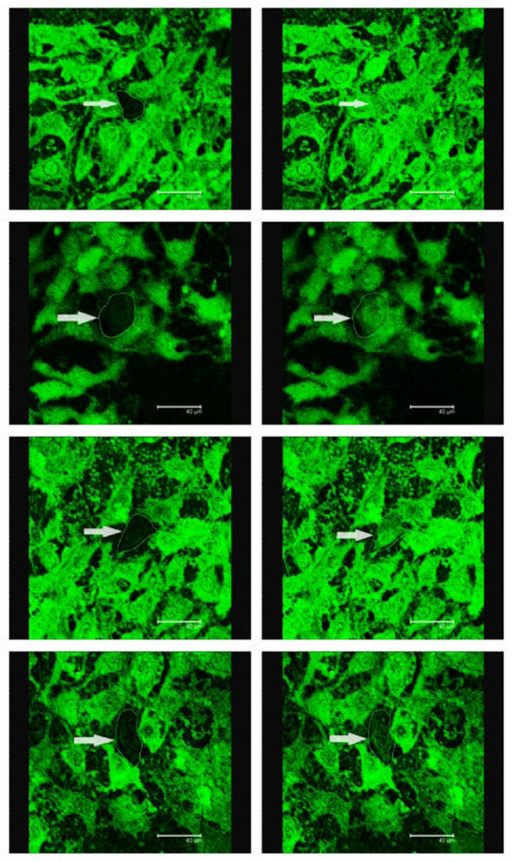

B
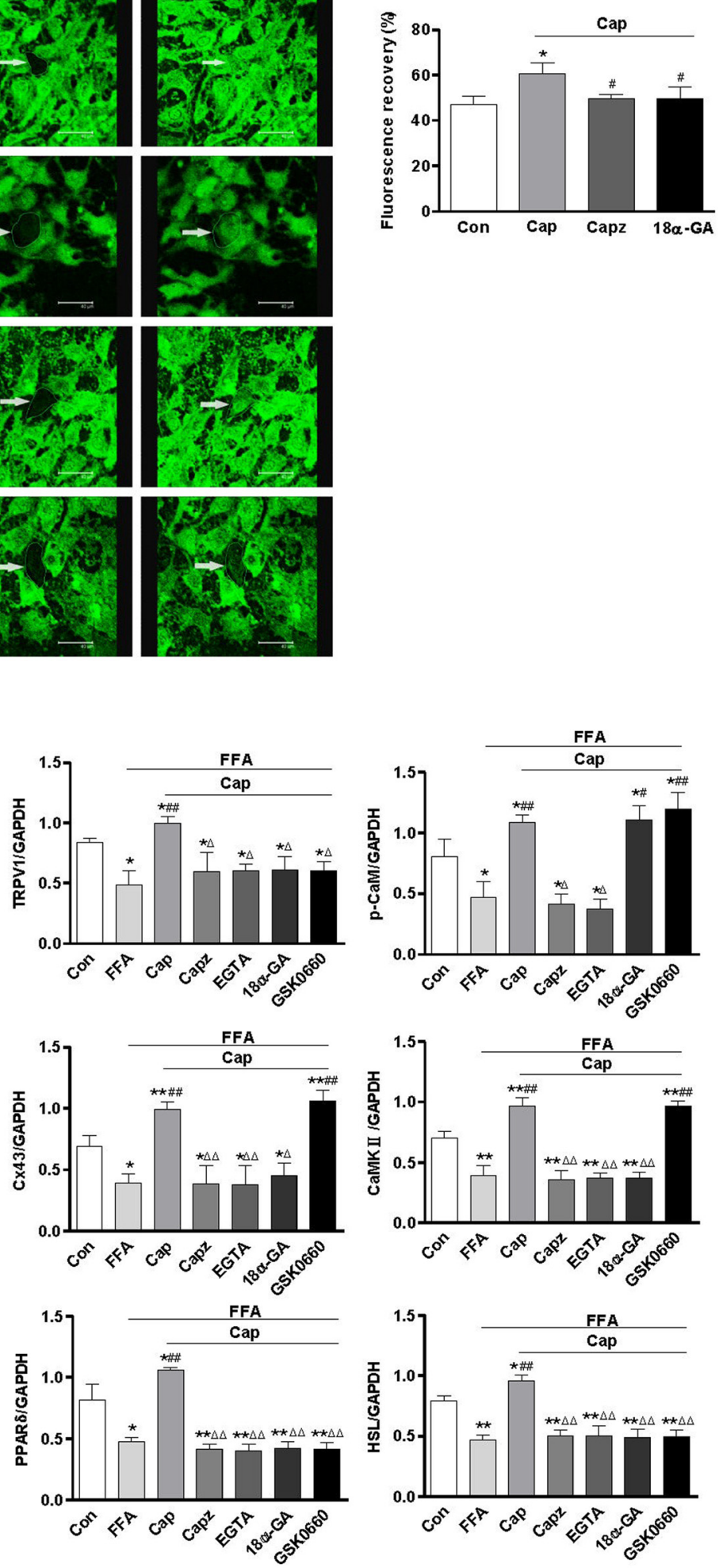

Figure $\mathbf{3}$ (See legend on next page.) 
(See figure on previous page.)

Figure 3 TRPV1 promotes lipolysis of 3T3-L1 preadipocytes through the regulation of Cx43-mediated intracellular calcium levels.

A. Images indicate the Fluorescence Recovery After Photobleaching (FRAP), after treatment with capsaicin (Cap), capsaicin + capsazepine (Capz) or capsaicin + 18a-GA (18a-GA) for 24 h, used to measure the dynamics of Cx43 mobility. B The ratio of fluorescence recovery inside the bleached regions. ${ }^{*} \mathrm{P}<0.05$ vs Con, ${ }^{\#} \mathrm{P}<0.05$ vs Cap. The values were expressed as the mean \pm SEM from 3 separate experiments. C. Immunoblots of TRPV1, p-CaM, CX43, CaMKII, PPARS, and HSL in 3T3-L1 preadipocytes treated with free fatty acids (FFA), FFA + capsaicin (Cap), FFA + capsaicin + capsazepine (Capz), FFA + capsaicin + EGTA (EGTA), FFA + capsaicin + 18a-GA (18a-GA) or FFA + capsaicin + GSK0660 (GSK0660, PPARס inhibitor, $10 \mu \mathrm{mol} / \mathrm{L})$ for $24 \mathrm{~h}$. ${ }^{*} \mathrm{P}<0.05$, ${ }^{* *} \mathrm{P}<0.01$ vs Con; ${ }^{\# P}<0.05$, ${ }^{\# \#} \mathrm{P}<0.01$ vs FFA; ${ }^{\Delta} \mathrm{P}<0.05,{ }^{\Delta \triangle} \mathrm{P}<0.01$ vs Cap. The densitometric values of protein expression levels were all normalized to GAPDH. Values are expressed as the mean $\pm \mathrm{SEM} ; \mathrm{n}=3$ per group.

(ND). However, long term dietary capsaicin significantly increased the expression levels of TRPV1, p-CaM, Cx43, CaMKII, PPAR $\delta$ and HSL in visceral adipose tissue from $\mathrm{db} / \mathrm{db}$ mice compared with $\mathrm{db} / \mathrm{db}$ ND group mice (Figure 4B). These results further confirm that TRPV1 activation by chronic capsaicin up-regulates $\mathrm{p}$-CaM, Cx43, CaMKII, PPAR $\delta$ and HSL in visceral adipose tissues from both humans and mice.

\section{TRPV1 activation by dietary capsaicin improves high-fat diet-induced obesity and lipid metabolism}

The body weights of WT and TRPV1 ${ }^{-1-}$ mice fed a highfat diet (HD) were significantly higher than those of the ND group mice after a 2-month intervention. Because chronic activation of TRPV1 by dietary capsaicin promoted lipolysis of visceral fat, we sought to determine whether TRPV1 activation by capsaicin reduced the body weight, food intake, serum TG, total cholesterol (TC), low-density lipoprotein cholesterol (LDL-C) and highdensity lipoprotein cholesterol (HDL-C). We found that chronic dietary capsaicin significantly reduced the body weights of WT mice fed a high-fat diet after 5 months, but that the effect was absent in TRPV1 ${ }^{-1-}$ mice (Figure 5A and B). The food intake was no difference between each group both in WT and TRPV1 $1^{-1-}$ mice. Dietary capsaicin also lowered serum lipid levels in WT mice fed a high-fat diet (Table 1). Thus, long-term dietary capsaicin lowers the body weight and serum lipid levels in mice fed a highfat diet.

\section{Discussion}

In this study, we found that functional TRPV1 coexpressed with $\mathrm{Cx} 43$ in both visceral adipose tissue and 3T3-L1 preadipocytes. TRPV1 activation by capsaicin increased intracellular calcium levels, affected the function of $\mathrm{Cx} 43$, and further promoted lipolysis in 3T3-L1 preadipocytes. Long-term chronic capsaicin increased the expression of $\mathrm{p}-\mathrm{CaM}, \mathrm{Cx} 43$, CaMKII, PPAR $\delta$ and HSL in visceral adipose tissues from WT and $\mathrm{db} / \mathrm{db}$ mice and obese humans. These results suggest that long-term dietary capsaicin promotes visceral fat remodeling and prevents high-fat-diet-induced obesity in mice by increasing the $\mathrm{Ca}^{2+}$ influx through the TRPV1 channels mediated by $\mathrm{Cx} 43$.
Capsaicin is the major pungent ingredient in chili peppers and is a highly selective agonist for the TRPV1 channels expressed in sensory neurons and adipose tissues [8,9]. TRPV1 is a non-selective cation channel that is permeable to $\mathrm{Na}^{+}, \mathrm{Ca}^{2+}$ and $\mathrm{Mg}^{2+}$ and mediates transmembrane cation flow after stimulated activation. TRPV1 is activated via phosphorylation by protein kinases, the calcium and calmodulin- dependent protein kinase II (CaMKII kinase) and cleavage of phosphatidylinositol 4, 5-bisphosphate (PIP2) by phospholipase C [35]. The Nterminus of TRPV1 has several phosphorylation sites for protein kinases which aid in its activation whereas TRPV1 desensitization results from its dephosphorylation by phosphatises [36]. Capsaicin activates TRPV1 resulting from extracellular calcium dependent conformational changes in the receptor protein, ultimately closing the channel pore. Extracellular calcium influx triggers the release of the intracellular calcium pool and enhances the intracellular free calcium concentration [37]. The movement of calcium ions through the cell membrane into the cell is considered a marker of the intracellular signaling pathway, and a series of basic activities affecting cellular energy metabolism is initiated. Intracellular calcium ions are considered important molecules in hypertension, insulin resistance, and obesity. Our previous study has shown that chronic activation of endothelial TRPV1 channel, which mediates an increased $\mathrm{Ca}^{2+}$ influx and subsequent phosphorylation of PKA and eNOS. TRPV1 activation by capsaicin might protect against hyperglycemia-induced endothelial dysfunction through a mechanism involving the PKA/ UCP2 pathway [38].

Moreover, a high-calcium diet can reduce lipid accumulation and promote lipolysis and weight loss [39]. In the early stages of adipocyte differentiation, increasing intracellular free calcium levels can prevent adipocyte differentiation and maturation [40]. Intracellular $\mathrm{Ca}^{2+}$ is one of the important signaling molecules of adipogenesis. Our previous studies showed that activation of TRPV1 by dietary capsaicin prevents obesity by inhibiting adipocyte differentiation and maturation with an increase in the induction of $\mathrm{Ca}^{2+}$ influx [20]. Therefore, intracellular free calcium regulates lipid metabolism and is related to adipocyte differentiation. 

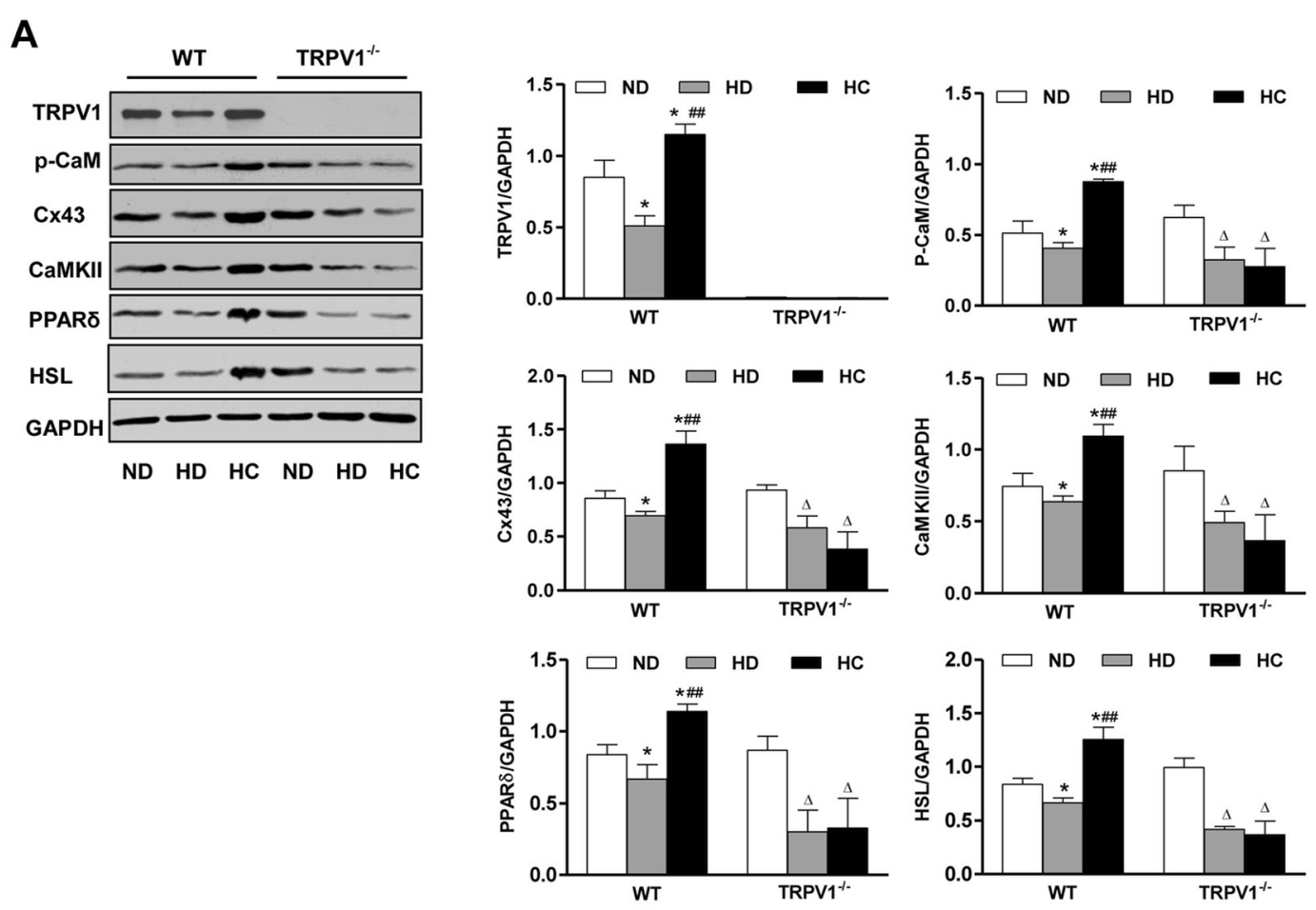

B
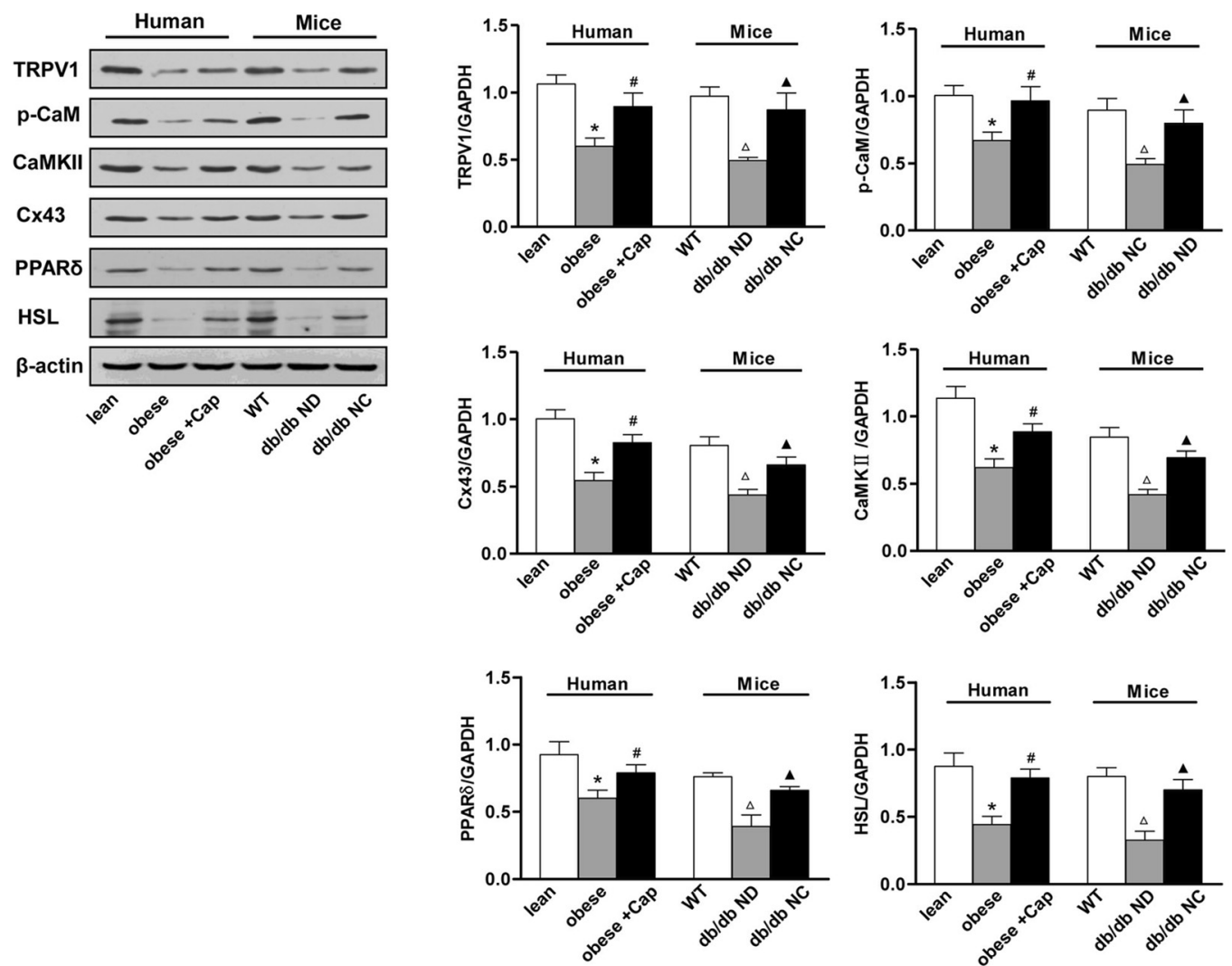

Figure 4 (See legend on next page.) 
(See figure on previous page.)

Figure 4 TRPV1 activation by dietary capsaicin increases Cx43-mediated lipolysis of mesenteric adipose tissues in mice and humans. A. Immunoblots of TRPV1, p-CaM, CX43, CaMKII, PPARS, and HSL in mesenteric adipose tissues from WT and TRPV1 ${ }^{-1-}$ mice fed a ND, HD and HC. ${ }^{*} \mathrm{P}<0.05$ vs. WT ND, ${ }^{\# \# P}<0.01$ vs. WT HD, ${ }^{\Delta} \mathrm{P}<0.05$ vs. TRPV1 ${ }^{-1-}$ ND. B. Immunoblots of TRPV1, $p-C a M, C \times 43$, CaMKII, PPARS, and HSL in visceral adipose tissues from humans and WT and db/db mice. Obese + Cap indicates that visceral adipose tissues from obese humans were treated with capsaicin for 24 hours. Db/db mice were fed a standard laboratory chow (db/db ND) or standard laboratory chow plus 0.01\% capsaicin (db/db NC). ${ }^{*} P<0.05$ vs lean people, ${ }^{\#} P<0.05$ vs obese people, ${ }^{\Delta} P<0.05$ vs WT, $\mathbf{P}<0.05 \mathrm{vs} \mathrm{db/db}$ ND. The densitometric values of protein expression levels were all normalized to GAPDH or $\beta$-actin. Values are expressed as the mean \pm SEM for 3 mice or people.

Some molecules play roles in lipid metabolism through calcium channels. Connexin is a direct channel regularly present between cells that regulates signal transduction, ions, amino acids, nucleotides, second messengers and other metabolic factors; it allows the passage of molecules with molecular weights less than $1000 \mathrm{Da}$ [41]. Calmodulin (CaM), a cytosolic $\mathrm{Ca}^{2+}$ binding protein, is a single-chain acidic protein with a weight of $16700 \mathrm{Da}$. $\mathrm{CaM}$ has four regions with similar structures that can be combined with calcium ions per molecule. When the intracellular calcium concentration transiently increases to $10 \sim 100$ times the extracellular calcium concentration, CaM is activated after binding to calcium ions and then combines with enzymes. The intracellular calcium concentration, regulated by calcium ions, is important for biochemical reactions. CaM is proposed to play a role in the $\mathrm{Ca}^{2+}$-induced uncoupling of gap junctions because CaM inhibitors were shown to prevent this response [42]. CaM binding sites were recently identified in the cytoplasmic loops of at least three $\alpha$-subfamily connexins (Cx43, Cx44, and Cx50).

Cx43 gap junctions are gated by a $\mathrm{Ca}^{2+} / \mathrm{CaM}-$ dependent mechanism involving the carboxyl-terminal quarter of the connexin cytoplasmic loop domain [43]. The amino acid residues in the Cx43- carboxyl terminus are targets of multifunctional protein kinases such as $\mathrm{Ca}^{2+} / \mathrm{CaM}$ protein kinase II (CaMKII), an enzyme known to play critical roles in $\mathrm{Ca}^{2+}$ homeostasis, transcription, apoptosis, and ischemic heart disease. The activity of CaMKII is important for regulating Cx43 in normal and

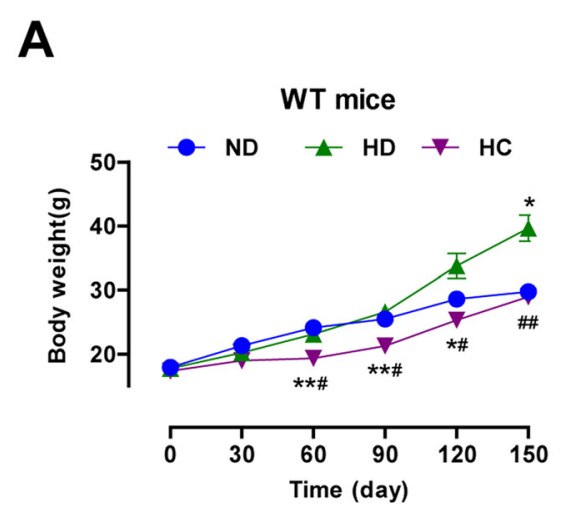

B
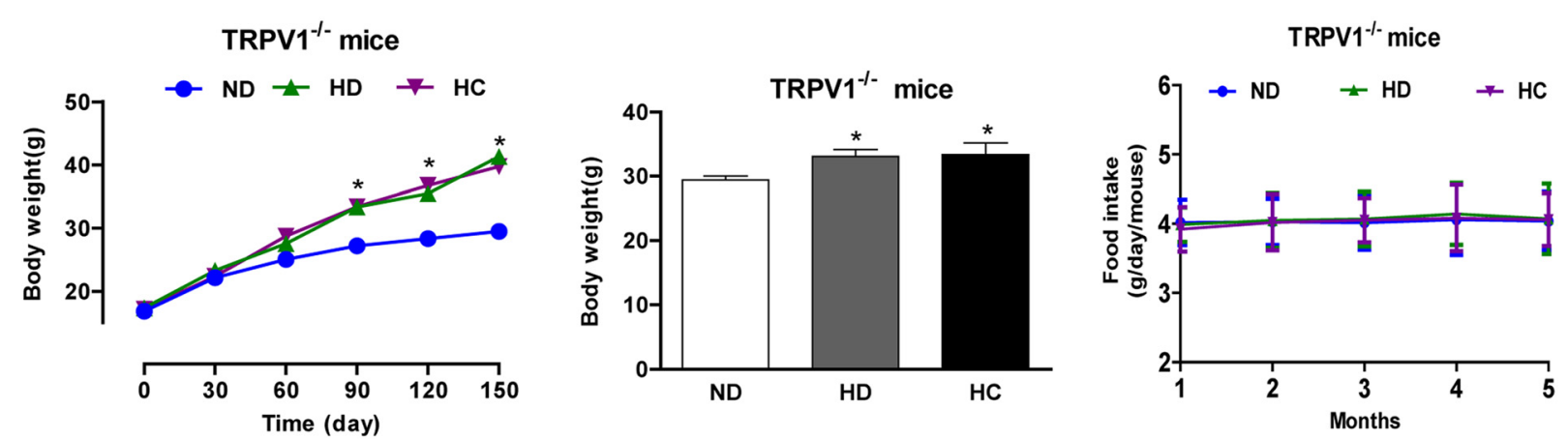

Figure 5 TRPV1 activation by dietary capsaicin improves high-fat diet-induced obesity. A and $\mathbf{B}$. Body weight gain and food intake of WT $\mathbf{A}$ and TRPV1 ${ }^{-1-}$ B mice fed with ND, HD and HC. The values are expressed as the mean \pm SEM for 15 mice. ${ }^{*} P<0.05$, ${ }^{*} P<0.01$ Vs. ND, ${ }^{\#} \mathrm{P}<0.01$ vs. HD. 
diseased tissues [44]. Cx43 is the main junction protein in the differentiation and proliferation of adipocytes. The inhibition of Cx43 expression and function induces osteoblast trans-differentiation into adipocytes and allows muscle cells to differentiate into adipocytes [45]. Furthermore, the inhibition of gap junctions promotes osteoblast cell differentiation into adipocytes and the expression of lipoprotein lipase and PPAR 2 , resulting in lipid droplet accumulation [46]. In the process of 3T3-L1 preadipocyte differentiation, the connexin inhibitor, $18 \alpha-\mathrm{GA}$, or Cx43 RNA interference inhibits 3T3-L1 cell differentiation and reduces the expression levels of PPAR 2 and GLUT4 in mature adipocytes [23]. Therefore, gap junctions play important roles in adipocyte differentiation and lipid deposition.

Our results showed that the activation of a TRPV1induced calcium influx was reduced in the case of $\mathrm{Cx} 43$ inhibition. Previous studies showed that the $\mathrm{Ca}^{2+}$ status between cells is affected by adjusting the gap junction [47]; connexin expression affects the transmission of information between cells, including the transfer of $\mathrm{Ca}^{2+}$ [48]. Calcium influx and calcium ion permeability are closely related given that $\mathrm{Ca}^{2+}$-dependent ATP inhibitors reduce the transient influx of $\mathrm{Ca}^{2+}$. Others found that in neonatal rat cultured myocytes, dominant-negative (DN) inhibition of Cx43 impaired intercellular coupling and desynchronized $\mathrm{Ca}^{2+}$ transients among individual cells [49]. The status of gap junction channels is related to the intracellular $\mathrm{pH}$ value, ionic changes, cAMP inhibition, $\mathrm{Cx}$ protein phosphorylation and genetic factors. The level of intracellular $\mathrm{Ca}^{2+}$ is one of the important factors that affect the permeability of connexin expression. The intracellular $\mathrm{Ca}^{2+}$ concentration influences connexin function [50], and intracellular calcium overload in ventricular myocytes affects the coupling function between cells [51]. Thus, Cx43 activity is affected by intracellular free $\mathrm{Ca}^{2+}$ and regulates intracellular calcium levels.

Peroxisome proliferator activated receptor (PPAR) $\delta$ and hormone sensitive lipase (HSL) play critical roles in energy balance, including TG metabolism, fatty acid handling and storage, and glucose homeostasis; the dysregulation of these processes characterizes obesity, diabetes, and atherosclerosis. PPARs are ligand-activated nuclear receptors that are involved in the transcriptional regulation of energy balance and inflammation. Nutrients such as fatty acids direct cellular biology by inducing specific transcriptional responses in the nucleus. PPARs are involved in a mechanism through which nutrient-driven transcriptional regulation can occur [52]. Recent studies suggest that PPAR $\delta$ regulates lipid metabolism in adipocytes both in vitro and in vivo. PPAR $\delta$ therapies have complementary effects in improving lipoprotein subfractions associated with atherogenic dyslipidemia [53]. Pharmacological activation of PPAR $\delta$ inhibited lipogenesis in high-fat dietinduced diabetic mice [54]. The release of free fatty acids from fat stores requires the enzymatic activity of lipases. Mobilization of fatty acids from TG stores in adipose tissue requires lipolytic enzymes. HSL is the only ratelimiting enzyme in the lipolysis of TG stored in adipocytes, and the classical lipolytic PKA/HSL pathway is activated by isoproterenol, forskolin and IBMX [55]. Genetic activation of HSL in mice decreases the adipose mass and leads to triacylglycerol deposition in multiple tissues. A high-fat diet induces the suppression of HSL and AMPK signaling in lipolysis and the utilization of lipids in visceral and subcutaneous adipocytes, which may play an important role in the defective lipid mobilization and metabolism observed in diet-induced obesity [56]. HSL participates in lipolysis through fatty acid $\beta$-oxidation [57], while PPAR $\delta$ activation can increase the levels of HSL and CPT1 in adipose tissue [58]. Our previous study also showed that chronic dietary capsaicin promotes the lipolysis of fatty liver by up-regulating HSL and PPAR $\delta$ in WT mice [21]. The present study showed that TRPV1 activation increased the expression levels of $\mathrm{Cx} 43$, p-CaM and CaMKII through an increased intracellular free calcium concentration and triggered a series of physiological cellular activities. The up-regulation of p-CaM and CaMKII activated PPAR $\delta$ and HSL and promoted lipolysis.

Our previous studies showed that capsaicin activates TRPV1 and promotes extracellular $\mathrm{Ca}^{2+}$ influx $[41,59]$, whereas the present study showed that TRPV1 activation enhances the function of gap junctions, increases extracellular $\mathrm{Ca}^{2+}$ influx and activates $\mathrm{Cx} 43$. Therefore, we showed that TRPV1 activation induces an influx of calcium mediated by $\mathrm{Cx} 43$, and furthermore that $\mathrm{Cx} 43$ influenced intracellular $\mathrm{Ca}^{2+}$ levels to promote lipolysis and visceral fat remodeling.

Table 1 Biochemical characteristics of WT and TRPV1 ${ }^{-1-}$ mice

\begin{tabular}{|c|c|c|c|c|c|c|}
\hline & \multicolumn{3}{|l|}{ WT mice } & \multicolumn{3}{|c|}{ TRPV $^{-1-}$ mice } \\
\hline & $\mathrm{ND}(n=15)$ & $H D(n=15)$ & $H C(n=15)$ & $\mathrm{ND}(n=15)$ & $H D(n=15)$ & $\mathrm{HC}(\mathrm{n}=15)$ \\
\hline$\overline{\mathrm{TG}}(\mathrm{mmol} / \mathrm{l})$ & $0.71 \pm 0.04$ & $1.04 \pm 0.10^{* *}$ & $0.70 \pm 0.04^{\#}$ & $0.68 \pm 0.13$ & $0.91 \pm 0.06^{*}$ & $0.87 \pm 0.07^{*}$ \\
\hline $\mathrm{TC}(\mathrm{mmol} / \mathrm{l})$ & $2.10 \pm 0.15$ & $3.16 \pm 0.19^{* *}$ & $2.76 \pm 0.48^{\#}$ & $1.97 \pm 0.21$ & $2.46 \pm 0.15^{*}$ & $2.26 \pm 0.18^{*}$ \\
\hline LDL-C (mmol/l) & $0.84 \pm 0.07$ & $1.14 \pm 0.04^{* *}$ & $0.97 \pm 0.03^{\#}$ & $0.86 \pm 0.11$ & $1.01 \pm 0.05^{*}$ & $0.97 \pm 0.02^{*}$ \\
\hline HDL-C (mmol/l) & $0.81 \pm 0.09$ & $0.85 \pm 0.09$ & $0.65 \pm 0.18$ & $0.79 \pm 0.38$ & $0.80 \pm 0.10$ & $0.82 \pm 0.11$ \\
\hline
\end{tabular}

Data are mean \pm SEM for 15 mice. ${ }^{*} \mathrm{P}<0.05,{ }^{* *} \mathrm{P}<0.01$ vs. WT ND, ${ }^{\#} \mathrm{P}<0.05$ vs. WT HD. 


\section{Conclusions}

In conclusion, we provided new evidence that TRPV1 activation by dietary capsaicin promotes visceral fat remodeling through the up-regulation of $\mathrm{Cx} 43$, which may represent a novel strategy for the management of obesity. Thus, dietary capsaicin may represent a promising lifestyle intervention in populations that are at high risk for obesity.

\section{Abbreviations \\ TRPV1: Transient receptor potential vanilloid 1; Cx43: Connexin43; WT: Wild-type; 18a-GA: 18 alpha-glycyrrhetinic acid; GJC: Gap-junctional communication; FFA: Free fatty acids; FRAP: Fluorescence replacement after photobleaching; HD: High-fat diet; TC: Total cholesterol; LDL-C: Low-density lipoprotein cholesterol; HDL-C: High-density lipoprotein cholesterol; CaM: Calmodulin; CaMKII: $\mathrm{Ca}^{2+} / \mathrm{CaM}$ protein kinase II; PPAR: Peroxisome proliferator activated receptor; HSL: hormone sensitive lipase.}

\section{Competing interests}

The authors declare that they have no competing interests.

\section{Authors' contributions}

Participated in research design: JC, LL, DYL, ZCY and ZMZ; conducted experiments: JC, LL, YSL, XL, QQS, HY, JZ, YXN and JC; performed data analysis and interpretation: ZGZ, PG, BW; JC, LL, DYL, ZCY and ZMZ contributed to the writing of the manuscript and critically revised the manuscript: all authors read and approved the final manuscript.

\section{Acknowledgements}

The authors thank Tingbing Cao, and Lijuan Wang (Chongqing Institute of Hypertension, China) for technical assistance.

This study was funded by the National Basic Research Program of China (2013CB531104, and 2012CB517806) and Natural Science Foundation of China (91339112 and 81300704, 81070669, 81270392).

No potential conflicts of interest relevant to this article were reported.

\section{Received: 1 November 2014 Accepted: 24 January 2015}

\section{Published online: 13 February 2015}

\section{References}

1. Gutierrez-Aguilar R, Kim DH, Woods SC, Seeley RJ. Expression of new loci associated with obesity in diet-induced obese rats: from genetics to physiology. Obesity (Silver Spring). 2012;20(2):306-12.

2. Després JP. Abdominal obesity and cardiovascular disease: is inflammation the missing link? Can J Cardiol. 2012;28(6):642-52.

3. de Souza RJ, Bray GA, Carey VJ, Hall KD, LeBoff MS, Loria CM, et al. Effects of 4 weight-loss diets differing in fat, protein, and carbohydrate on fat mass, lean mass, visceral adipose tissue, and hepatic fat: results from the POUNDS LOST trial. Am J Clin Nutr. 2012:95(3):614-25.

4. Despres JP, Lemieux I. Abdominal obesity and metabolic syndrome. Nature. 2006:444(7121):881-7.

5. Fox CS, Massaro JM, Hoffmann U, Pou KM, Maurovich-Horvat P, Liu CY, et al. Abdominal visceral and subcutaneous adipose tissue compartments: association with metabolic risk factors in the Framingham Heart Study. Circulation. 2007:116(1):39-48.

6. Mathieu P, Pibarot P, Larose E, Poirier P, Marette A, Despres JP. Visceral obesity and the heart. Int J Biochem Cell Biol. 2008;40(5):821-36.

7. Nilius B, Owsianik G. The transient receptor potential family of ion channels. Genome Biol. 2011:12(3):218.

8. Carmona Marinetto A, Lorenzo J. Intelligibility of language as a function of its consonant sounds. Study conducted in adult individuals with normal hearing. Acta Otorrinolaringol Esp. 1988;39(3):158-60

9. Lorenzo R. Diffuse interstitial pulmonary fibrosis in tobacco-industry workers. Arch Monaldi Mal Torace. 1988:43(3):235-41.

10. Corsi M, Lorenzon G, Mesaglio S. Hepatic echography in acute viral hepatitis. Radiol Med. 1988;75(6):638-42.

11. Yoshioka M, Lim K, Kikuzato S, Kiyonaga A, Tanaka H, Shindo M, et al. Effects of red-pepper diet on the energy metabolism in men. J Nutr Sci Vitaminol. 1995:41(6):647-56.
12. Yoshioka M, St-Pierre S, Suzuki M, Tremblay A. Effects of red pepper added to high-fat and high-carbohydrate meals on energy metabolism and substrate utilization in Japanese women. Br J Nutr. 1998;80(6):503-10.

13. Marshall NJ, Liang L, Bodkin J, Dessapt-Baradez C, Nandi M, Collot-Teixeira S, et al. A role for TRPV1 in influencing the onset of cardiovascular disease in obesity. Hypertension. 2013;61(1):246-52.

14. Gram DX, Ahren B, Nagy I, Olsen UB, Brand CL, Sundler F, et al. Capsaicinsensitive sensory fibers in the islets of Langerhans contribute to defective insulin secretion in Zucker diabetic rat, an animal model for some aspects of human type 2 diabetes. Eur J Neurosci. 2007;25(1):213-23.

15. Josse AR, Sherriffs SS, Holwerda AM, Andrews R, Staples AW, Phillips SM. Effects of capsinoid ingestion on energy expenditure and lipid oxidation at rest and during exercise. Nutr Metab. 2010;7:65.

16. Lee TA, Li Z, Zerlin A, Heber D. Effects of dihydrocapsiate on adaptive and diet-induced thermogenesis with a high protein very low calorie diet: a randomized control trial. Nutr Metab. 2010;7:78.

17. Lejeune MP, Kovacs EM, Westerterp-Plantenga MS. Effect of capsaicin on substrate oxidation and weight maintenance after modest body-weight loss in human subjects. Br J Nutr. 2003;90(3):651-9.

18. Motter AL, Ahern GP. TRPV1-null mice are protected from diet-induced obesity. FEBS Lett. 2008;582(15):2257-62.

19. Baboota RK, Singh DP, Sarma SM, Kaur J, Sandhir R, Boparai RK, et al. Capsaicin induces "brite" phenotype in differentiating 3T3-L1 preadipocytes. PLoS One. 2014;9(7):e103093.

20. Zhang LL, Yan Liu D, Ma LQ, Luo ZD, Cao TB, Zhong J, et al. Activation of transient receptor potential vanilloid type-1 channel prevents adipogenesis and obesity. Circ Res. 2007:100(7):1063-70.

21. Li Q, Li L, Wang F, Chen J, Zhao Y, Wang P, et al. Dietary capsaicin prevents nonalcoholic fatty liver disease through transient receptor potential vanilloid 1-mediated peroxisome proliferator-activated receptor delta activation. Pflugers Arch. 2013;465(9):1303-16

22. Lorenzo M, Roncero C, Fabregat I, Benito M. Hormonal regulation of rat foetal lipogenesis in brown-adipocyte primary cultures. Biochem J. 1988;251 (2):617-20.

23. Yanagiya T, Tanabe A, Hotta K. Gap-Junctional Communication Is Required for Mitotic Clonal Expansion during Adipogenesis. Obesity. 2007;15(3):572-82.

24. Yeganeh A, Stelmack GL, Fandrich RR, Halayko AJ, Kardami E, Zahradka P. Connexin 43 phosphorylation and degradation are required for adipogenesis. Biochim Biophys Acta. 2012;1823(10):1731-44.

25. Song D, Liu X, Liu R, Yang L, Zuo J, Liu W. Connexin 43 hemichanne regulates $\mathrm{H} 9 \mathrm{C} 2$ cell proliferation by modulating intracellular ATP and $\left[\mathrm{Ca}^{2+}\right]$ Acta Biochim Biophys Sin (Shanghai). 2010;42(7):472-82.

26. Cappelluti $G$, Busilacchi P, Lorenzoni A. Surgical treatment of tumors of the extrahepatic bile ducts. Report on 5 years. Minerva Chir. 1988;43(11):929-33.

27. Szatkowski C, Vallet J, Dormishian M, Messaddeq N, Valet P, Boulberdaa M, et al. Prokineticin Receptor 1 as a Novel Suppressor of Preadipocyte Proliferation and Differentiation to Control Obesity. PLoS One. 2013;8(12):e81175.

28. Velasquez Almonacid L, Tafuri S, Dipineto L, Matteoli G, Fiorillo E, Morte RD, et al. Role of connexin- 43 hemichannels in the pathogenesis of Yersinia enterocolitica. Vet J. 2009:182(3):452-7.

29. Kamioka H, Ishihara Y, Ris H, Murshid SA, Sugawara Y, Takano-Yamamoto T, et al. Primary cultures of chick osteocytes retain functional gap junctions between osteocytes and between osteocytes and osteoblasts. Microsc Microanal. 2007;13(2):108-17.

30. Gomes P, Srinivas SP, Vereecke J, Himpens B. Gap junctional intercellular communication in bovine corneal endothelial cells. Exp Eye Res. 2006:83(5):1225.

31. Shen J, Wang L, Zheng L, Zhu J, Hu S. Lovastatin inhibits gap junctional communication in cultured aortic smooth muscle cells. J Cardiovasc Pharmacol Ther. 2010:15(3):296-302.

32. Oviedo-Orta E, Howard Evans W. Gap junctions and connexin-mediated communication in the immune system. Biochim Biophys Acta. 2004;1662(1-2):102-12

33. Sung B, Prasad S, Ravindran J, Yadav VR, Aggarwal BB. Capsazepine, a TRPV1 antagonist, sensitizes colorectal cancer cells to apoptosis by TRAlL through ROS-JNK-CHOP-mediated upregulation of death receptors. Free Radic Biol Med. 2012;53(10):1977-87.

34. Haq N, Grose D, Ward E, Chiu O, Tigue N, Dowell SJ, et al. A high-throughput assay for connexin 43 (Cx43, GJA1) gap junctions using codon-optimized aequorin. Assay Drug Dev Technol. 2013;11(2):93-100.

35. Mohapatra DP, Nau C. Desensitization of capsaicin-activated currents in the vanilloid receptor TRPV1 is decreased by the cyclic AMP-dependent protein kinase pathway. J Biol Chem. 2003;278(50):50080-90. 
36. Ma W, Quirion R. Inflammatory mediators modulating the transient receptor potential vanilloid 1 receptor: therapeutic targets to treat inflammatory and neuropathic pain. Expert Opin Ther Targets. 2007;11(3):307-20.

37. Marín J, Encabo A, Briones A, García-Cohen E-C, Alonso MJ. Mechanisms involved in the cellular calcium homeostasis in vascular smooth muscle: Calcium pumps. Life Sci. 1998;64(5):279-303.

38. Sun J, Pu Y, Wang P, Chen S, Zhao Y, Liu C, et al. TRPV1-mediated UCP2 upregulation ameliorates hyperglycemia-induced endothelial dysfunction. Cardiovasc Diabetol. 2013;12:69.

39. Zemel MB. Regulation of adiposity and obesity risk by dietary calcium: mechanisms and implications. J Am Coll Nutr. 2002;21(2):146S-51.

40. Argilés JM, López-Soriano FJ, Busquets S. Therapeutic potential of interleukin-15: a myokine involved in muscle wasting and adiposity. Drug Discov Today. 2009;14(3):208-13.

41. Zhang SW, Liu Y, Huang GZ, Liu L. Aconitine alters connexin43 phosphorylation status and $\left[\mathrm{Ca}^{2+}\right]$ oscillation patterns in cultured ventricular myocytes of neonatal rats. Toxicol In Vitro. 2007;21(8):1476-85.

42. Peracchia $C$, Sotkis $A$, Wang XG, Peracchia LL, Persechini A. Calmodulin directly gates gap junction channels. J Biol Chem. 2000;275(34):26220-4.

43. Xu Q, Kopp RF, Chen Y, Yang JJ, Roe MW, Veenstra RD. Gating of connexin 43 gap junctions by a cytoplasmic loop calmodulin binding domain. Am J Physiol Cell Physiol. 2012;302(10):C1548-56.

44. Huang RY, Laing JG, Kanter EM, Berthoud VM, Bao M, Rohrs HW, et al. Identification of CaMKIl phosphorylation sites in Connexin43 by highresolution mass spectrometry. J Proteome Res. 2011;10(3):1098-109.

45. Yamanouchi K, Yada E, Ishiguro N, Nishihara M. 18 alpha-glycyrrhetinic acid induces phenotypic changes of skeletal muscle cells to enter adipogenesis. Cell Physiol Biochem. 2007;20(6):781-90.

46. Schiller PC, D'Ippolito G, Brambilla R, Roos BA, Howard GA. Inhibition of gap-junctional communication induces the trans-differentiation of osteoblasts to an adipocytic phenotype in vitro. J Biol Chem. 2001;276(17):14133-8.

47. Boitano S, Dirksen ER, Evans WH. Sequence-specific antibodies to connexins block intercellular calcium signaling through gap junctions. Cell Calcium. 1998;23(1):1-9.

48. Cotrina ML, Lin JH-C, Alves-Rodrigues A, Liu S, Li J, Azmi-Ghadimi H, et al. Connexins regulate calcium signaling by controlling ATP release. Proc Natl Acad Sci U S A. 1998;95(26):15735-40.

49. Nakagami T, Tanaka H, Dai P, Lin SF, Tanabe T, Mani H, et al. Generation of reentrant arrhythmias by dominant-negative inhibition of connexin43 in rat cultured myocyte monolayers. Cardiovasc Res. 2008;79(1):70-9.

50. Schalper KA, Sánchez HA, Lee SC, Altenberg GA, Nathanson MH, Sáez JC. Connexin 43 hemichannels mediate the $\mathrm{Ca}^{2+}$ influx induced by extracellular alkalinization. Am J Physiol Cell Physiol. 2010;299(6):C1504-15.

51. Kurebayashi N, Nishizawa H, Nakazato Y, Kurihara H, Matsushita S, Daida H, et al. Aberrant cell-to-cell coupling in $\mathrm{Ca}^{2+}$-overloaded guinea pig ventricular muscles. Am J Physiol Cell Physiol. 2008;294(6):C1419-29.

52. Ahmed W, Ziouzenkova O, Brown J, Devchand P, Francis S, Kadakia M, et al. PPARs and their metabolic modulation: new mechanisms for transcriptional regulation? J Intern Med. 2007;262(2):184-98.

53. Tesauro B, Negro G, Percopo V, Lorenzo M. Thymectomy and myasthenia gravis. Critical remarks on our experience. Minerva Chir. 1988;43(17):1319-22.

54. Desjardins JG, Bass J, Leboeuf G, Di Lorenzo M, Letarte J, Khan AH, et al. A twenty-year experience with thyroid carcinoma in children. J Pediatr Surg. 1988;23(8):709-13.

55. Di Lorenzo M, Collin PP. Pulmonary metastases in children: results of surgical treatment. J Pediatr Surg. 1988;23(8):762-5.

56. de Lorenzo V, Herrero M, Neilands JB. IS1-mediated mobility of the aerobactin system of pColV-K30 in Escherichia coli. Mol Gen Genet. 1988;213(2-3):487-90.

57. Jensen-Urstad AP, Semenkovich CF. Fatty acid synthase and liver triglyceride metabolism: Housekeeper or messenger? Biochim Biophys Acta. 2012;1821(5):747-53.

58. He H, Yang D, Ma L, Luo Z, Ma S, Feng X, et al. Telmisartan prevents weight gain and obesity through activation of peroxisome proliferator-activated receptor-delta-dependent pathways. Hypertension. 2010;55(4):869-79.

59. Yang D, Luo Z, Ma S, Wong WT, Ma L, Zhong J, et al. Activation of TRPV1 by dietary capsaicin improves endothelium-dependent vasorelaxation and prevents hypertension. Cell Metab. 2010;12(2):130-41.

\section{Submit your next manuscript to BioMed Central and take full advantage of:}

- Convenient online submission

- Thorough peer review

- No space constraints or color figure charges

- Immediate publication on acceptance

- Inclusion in PubMed, CAS, Scopus and Google Scholar

- Research which is freely available for redistribution

Submit your manuscript at www.biomedcentral.com/submit 